\title{
The profile of patients' complaints in a regional hospital
}

\author{
Alireza Jabbari ${ }^{1}$, Elahe Khorasani ${ }^{2}$, Marzie Jafarian Jazi ${ }^{3, *}$, Maryam Mofid $^{4}$, Raja Mardani ${ }^{5}$
}

\begin{abstract}
Background: A hospital should be an institution of understanding and respecting patients' rights, their families, physicians and other caregivers. Hospitals and all other healthcare centers must be cautious toward respecting ethical aspects of care and treatment. On the other hand, patients' satisfaction reflects capabilities of physicians and medical staff as well as the extent patients' rights and treatment quality are observed. Nowadays, complaints handling is considered as an essential component of healthcare system in line with promoting health standards. In the present study, researchers attempt to identify the resources, individuals, complained issues, and measures which are considered to handle these issues in a regional hospital.

Methods: We employed a descriptive, cross-sectional study to conduct this research. The research population included cases registered at the complaints unit of one of the hospitals in Isfahan in selected months of 2012 to 2013 . The data were collected through observation of available documents. Excel software program was used for data analysis.

Results: Findings indicate that despite a decrease in the total number of complaints, there was an increase in the number of complaints about medical staff. Nursing staff were considered as the second highly complained unit during the study period. Conclusion: Results obtained from the present study can be taken as experiences to modify and amend the hospital's future performance. In general, the existence of complaints in a system is an indication of gaps when providing healthcare services. Creating an organized system to collect complaints and reviewing them helps hospitals to be cognizant of their defects and plan to prevent their reoccurrence.

Keywords: Complaint, Patient's Rights, Hospitals, Patients' Satisfaction, Iran

Copyright: (C) 2014 by Kerman University of Medical Sciences

Citation: Jabbari A, Khorasani E, Jafarian Jazi M, Mofid M, Mardani R. The profile of patients' complaints in a regional hospital. Int J Health Policy Manag 2014; 2: 131-135. doi: 10.15171/ijhpm.2014.36
\end{abstract}

Article History:

Received: 24 December 2013 Accepted: 4 April 2014 ePublished: 10 April 2014

*Correspondence to: Marzie Jafarian Jazi Email: Jafarian_86@yahoo.com

\section{Introduction}

Based on modern management theories, paying attention to customer orientation and clients' satisfaction is considered as one of the major approaches. In administrative and executive systems, people's satisfaction with governmental services is taken as one of the indices to measure efficiency, growth and development, and components such as quality of servicing, the quality of treating with service receivers, and informing are appropriate factors which may satisfy service receivers and clients of governmental agencies (1). In addition, the role of quality in the success or failure of organizations is so remarkable that only those organizations which consider the main axis of their own activities can meet their clients' demands and satisfy the clients' needs with the minimum of prices and the maximum of quality (2).

In recent decades, the Global Campaign for the Defense of Human Rights has attracted the attention of international scientific communities toward the rights of social groups particularly patients. As patients are one of the most susceptible social groups in psychological, social and economic terms, international communities for human rights pay much attention to the notion of patients' rights (3).

Hospitals should be considered as institutions of discernment and respect for patients' rights, their families, practitioners, and nurses. Hospitals and other healthcare service centers should be careful of respecting moral aspects of care and treatment (4). In addition, patients' satisfaction reflects practitioners' and medical caregivers' capabilities, the extent of meeting patient's rights and treatment quality (2).

In addition, it is noteworthy that justice, as one of the most significant aspects of ethics, influences attitudes and perceptions in various domains; overlooking this principle results in dissatisfaction and complaints (5). Despite the efforts of medical community, healthcare staff, and advances in medical technology, the rate of dissatisfaction and complaints is increasing. Although this might be the result of medical malpractices, but it could be rooted in doctors' failure to communicate well with patients (6). It seems that, if patients' bill of rights is to enjoy its appropriate status in the society, extensive research on patient's complaints seems necessary (7) because handling complaints means determining the causes, organizing actions, and identifying valid sources to handle the causes of complaints.

In a cross-sectional descriptive study, Hedayati et al. examined all cases of complaints about physicians' medical malpractices in various specialized fields in which they were filled by Isfahan's Forensic Medicine Department in 2009 and 2010 (8). Furthermore, Hejazi et al. carried out a retrospective descriptive research on all complaint cases filed by Orumieh-based Medical Council against pediatricians during a period of ten years. Findings indicated that in all cases, it was the child's father who had filed a complaint; most of the complaints cases were against state non-academic centers and most of malpractices were of imprudent kinds (9). 
In a study titled as "investigating the Negligence Frequency of General Practitioners in complaints referred to Tehran's Commission for Forensic Medicine", Rafizadeh Tabai Zavareh et al. investigated all cases against general practitioners referred to the Commission Center of Teheran from 2003 to 2005 and found that the most reasons of medical malpractices were due to failure in appropriate treatment and medication. The findings of their study are consistent with those of the present study (10). Mirza Aghai et al. in their investigation of complaints recorded at three hospitals affiliated with Tehran University of Medical Sciences surveyed 363 cases of complaints filed with hospitals. Most of complaints were about postponed or cancelled medical visits and improper behavior at $29.7 \%$ and $24 \%$ respectively (11). Taking proper actions to remove problems and prevent their reoccurrences is also essential and requires attention (12). In fact, by handling the complaints in the healthcare centers, the domains of malpractices and patients' dissatisfaction are identifiable while principles and solutions can be proposed to correct organizational and human issues (13). In other words, by dealing with the results of complaints, the causes and factors of dissatisfaction and complaints could be determined and consequently removed. It is noteworthy that the rate of registered complaints does not reflect the actual organizational dissatisfaction, but just states some aspects of reality because the fear from the consequences prevents patients to complain about their situations. Nowadays, dealing with complaints is considered as an essential component of healthcare systems to promote health standards.

Accordingly, this paper investigates the state of handling complaints in a principal teaching hospital and tries to identify the challenges facing the process and take action to improve it. The objectives of the present study are to identify the frequency distribution of the people complained about, the units complained about, the total number of complaints, and frequency distribution of the results of complaints.

\section{Methods}

This research is a descriptive, retrospective cross-sectional study in which its data was collected after obtaining permission from respective authorities. The population included cases registered at the complaints unit of a hospital in selected months of 2012 to 2013 and data were collected through observation and investigation of the existing documents. In the checklist of collecting data, the units complained about, the person complained about, and the results of complaints were investigated. The cause and resource of complaints issues were examined in this study, but their estimations were not possible due to the lack of accurate registration information.
For ethical considerations, data were kept as confidential and analyzed anonymously. For data analysis, Excel software program was employed.

\section{Results}

Findings of the present study show that the highest number of complaint cases against individuals (143 cases) was recorded in the second quarter of the year 2012 compared to other months of the year, and the lowest number (90 cases) was recorded in the last quarter of 2013. In the second quarter of 2012, the highest rate of complaints was filed against nursing staff $(35.7 \%)$ and the lowest rate of complaints (6.3\%) was filed against servicing staff. In the third quarter of 2012, the highest rate of complaints (39.5\%) was filed against medical staff and the lowest against administrative staff. In the fourth, the highest (42.9\%) and the lowest (7.6\%) numbers of complaints were filed against medical staff and servicing personnel, respectively. In the first quarter of 2013, the highest number of complaints was filed against medical staff (54.4\%) and the lowest against servicing personnel (3.3\%) (Table 1).

Findings indicate that despite the overall drop in the total number of complaints, the number of complaints about medical staff increased. The nursing staff were the next highly-complainedabout individuals during the investigated period (Table 1).

Findings show that in the third quarter of 2012 compared to other months of the investigated period, the highest number of complaints (229 cases) was filed against the hospital units while the lowest number of complaints against these units were filed in the first quarter of 2013 (94 cases). In the second quarter of 2012 , the highest number of complaints was filed against private booths (30.4\%) and the lowest was against special clinic (6.2\%). In the third quarter of 2012, the highest number of complaints was filed against administration and support units $(22.3 \%)$ and the lowest number was filed against food service units (3.1\%). In the fourth quarter of 2012, the highest number of complaints was filed against private booths (31.4\%) and the lowest number of complaints was filed against hygiene (9.5\%). In the first quarter of 2013, the highest number of complaints was filed against clinics $(42.6 \%)$ and the lowest number was against hygiene $(0.0 \%)$ (Table 2$)$.

The highest number of complaints was in the second quarter (348) and the lowest number of complaints (200) was in the last quarter (Table 3).

Throughout the second half of the investigated period except Feb-Mar, a significant percentage of complaints was solved at the complaint unit of the hospital. In Feb-Mar, however, a large number of complaints (47.1\%) was still pending. A larger proportion of complaints was also handled by other

Table 1. The frequency distribution of individuals complained about in the hospital divided into four quarters

\begin{tabular}{|c|c|c|c|c|c|c|c|c|}
\hline \multirow{2}{*}{ Complaints } & \multicolumn{2}{|c|}{$2^{\text {nd }}$ quarter (2012) } & \multicolumn{2}{|c|}{$3^{\text {nd }}$ quarter (2012) } & \multicolumn{2}{|c|}{$4^{\text {th }}$ quarter (2012) } & \multicolumn{2}{|c|}{$1^{\text {st }}$ quarter (2013) } \\
\hline & $\mathrm{N}$ & $\%$ & $\mathrm{~N}$ & $\%$ & $\mathrm{~N}$ & $\%$ & $\mathrm{~N}$ & $\%$ \\
\hline Medical staff & 48 & 33.6 & 47 & 39.5 & 51 & 42.9 & 49 & 54.4 \\
\hline Nursing staff & 51 & 35.7 & 37 & 31.1 & 47 & 39.5 & 28 & 31.1 \\
\hline Administrative staff & 20 & 14 & 9 & 7.6 & - & 0.0 & - & 0.0 \\
\hline Security staff & 15 & 10.5 & 13 & 10.9 & 12 & 10.1 & 10 & 11.1 \\
\hline Servicing staff & 9 & 6.3 & 13 & 10.9 & 9 & 7.6 & 3 & 3.3 \\
\hline Total & 143 & 100 & 119 & 100 & 119 & 100 & 90 & 100 \\
\hline
\end{tabular}


Table 2. The frequency distribution of the units complained about in the hospital divided into quarters

\begin{tabular}{|c|c|c|c|c|c|c|c|c|}
\hline \multirow{2}{*}{ Complaints } & \multicolumn{2}{|c|}{$2^{\text {nd }}$ quarter (2012) } & \multicolumn{2}{|c|}{$3^{\text {nd }}$ quarter (2012) } & \multicolumn{2}{|c|}{$4^{\text {th }}$ quarter (2012) } & \multicolumn{2}{|c|}{$1^{\text {st }}$ quarter (2013) } \\
\hline & $\mathrm{N}$ & $\%$ & $\mathrm{~N}$ & $\%$ & $\mathrm{~N}$ & $\%$ & $\mathrm{~N}$ & $\%$ \\
\hline Emergency department & 25 & 12.9 & 13 & 5.7 & 17 & 10.1 & 8 & 8.5 \\
\hline Clinic & 20 & 10.3 & 26 & 11.4 & 21 & 12.4 & 40 & 42.6 \\
\hline Special clinic & 12 & 6.2 & 18 & 7.9 & - & 0.0 & - & 0.0 \\
\hline Paraclinic units & 15 & 7.7 & 20 & 8.7 & 18 & 10.7 & 3 & 3.2 \\
\hline Administration and support units & 17 & 8.8 & 51 & 22.3 & - & 0.0 & - & 0.0 \\
\hline Food service units & 9 & 4.6 & 7 & 3.1 & 21 & 12.4 & 3 & 3.2 \\
\hline Facilities and equipment & 24 & 12.4 & 34 & 14.8 & 23 & 13.6 & 8 & 8.5 \\
\hline Hygiene & 13 & 6.7 & 17 & 7.4 & 16 & 9.5 & - & 0.0 \\
\hline Private booths & 59 & 30.4 & 43 & 18.8 & 53 & 31.4 & 32 & 34 \\
\hline Total & 194 & 100 & 229 & 100 & 169 & 100 & 94 & 100 \\
\hline
\end{tabular}

Table 3. Total number of complaints in the hospital divided by quarters

\begin{tabular}{ccccc}
\hline Complaints & $\mathbf{2}^{\text {nd }}$ quarter (2012) & $\mathbf{3}^{\text {nd }}$ quarter (2012) & $\mathbf{4}^{\text {th }}$ quarter (2012) & 1 $^{\text {st }}$ quarter (2013) \\
\hline Total & 337 & 348 & 318 & 200 \\
\hline
\end{tabular}

managements in this month. In Dec-Jan, around $57 \%$ of complaints remained unhandled. No feedback was given to complainants in Jan-Feb and Feb-Mar at 18.8\% and 20.4\%, respectively (Table 4 ).

\section{Discussion}

Findings show that complaints about medical staff increased throughout the studied period despite the decreasing number of total complaints. The nursing staff received the most complaints after the medical staff (Table 1). Haghi et al. concluded that patients complain about surgeons more than other physicians; while most of the time treatments were standard, they considered insufficient explanations of physicians in informing patients and the lack of providing sufficient information regarding the potential consequences of medical treatment as the causes of complaints in Mashhad-based Medical Council (14). Therefore, they maintain that enhancing doctor-patient relationship is an effective factor in preventing complaints. This issue shows the irrationality of complaints from a technical point of view which can be prevented through an appropriate doctor-patient relationship (13). Rangraz Jedi et al. in their study showed that about $67.74 \%$ of the patients' bills of rights were met in public hospitals of Kashan and it was necessary to increase the awareness of care providers and patients at the time of acceptance (15). Divided by the second half of the investigated period, results regarding individuals complained about indicate that the highest number of complaints was related to physicians and interns while the lowest number of complaints was about anesthesia and operating room technicians. The reason for these results seems to be physicians' and interns' unawareness of patients' bill of rights, which must be handled by training interns in the same way they learn medical issues. Technicians, on the other hand, have little contact with patients due to the nature of their job; and maybe that is the reason why they are less prone to complaints. Davati et al. proposed that the awareness level of $68.4 \%$ of physicians regarding patients' bill of rights was at medium level and there was a significant correlation between their score of awareness and years of practice. Physicians are not well aware of patients' bill of rights and an appropriate plan is needed to tackle this problem (16).

In a study on the skin and beauty-related complaints registered in Tehran-based department of Forensic Medicine from 2002 to 2010, Athar et al. names a number of factors which can reduce the number of complaints; these factors include: observing medical ethics and professional commitment, appropriate doctor-patient relationship, full explanation of the treatment process and its possible consequences, no exaggeration of treatment results, continuous study and upgrading medical knowledge, skilled and experienced physicians, avoiding methods not trained yet, choosing patients appropriately, and informed consent process regarding the high number of complaints about physicians in this study. These implications can be used for reducing such complaints (17).

Mirzaaghai et al. investigated complaints registered at three hospitals of Tehran University of Medical Sciences and their related factors. The highest number of complaints was claimed to be about physicians. This finding is consistent to the results of our study in some cases. Complaints about nurses were reported $10.2 \%$, while in our study nurses were less prone to complaints. About $59.1 \%$ of complaints were solved at the hospital which is in line with the present study. In general, they states that since delaying or cancelling sessions, and improper doctor-patient relationships are the issues most complained about, interference is necessary in these domains. Sharing the data of complaints among hospitals can be used to identify common problems and to plan strategies (11).

Most physicians and dentists working in Tehran who were complained about, did not do anything wrong according to experts of Medical Council and a large proportion of complaints were resulted from improper doctor-patient relationships. Behaviors based on physicians' professional commitment to patients can prevent a majority of complaints; in the aforementioned study, the causes of complaints were not registered, while registering them may help to identify and remove the weaknesses of this domain. In general, the quality of services and welfare were among the important issues of that research (18).

In a study carried out by Entman et al. it was shown that there 
Table 4. The frequency distribution of the results of complaints divided by months

\begin{tabular}{|c|c|c|c|c|c|c|c|c|c|c|c|c|}
\hline \multirow{2}{*}{ Results of complaints } & \multicolumn{2}{|c|}{ Sep-Oct } & \multicolumn{2}{|c|}{ Oct-Nov } & \multicolumn{2}{|c|}{ Nov-Dec } & \multicolumn{2}{|c|}{ Dec-Jan } & \multicolumn{2}{|c|}{ Jan-Feb } & \multicolumn{2}{|c|}{ Feb-Mar } \\
\hline & $\mathrm{N}$ & $\%$ & $\mathrm{~N}$ & $\%$ & $\mathrm{~N}$ & $\%$ & $\mathrm{~N}$ & $\%$ & $\mathrm{~N}$ & $\%$ & $\mathrm{~N}$ & $\%$ \\
\hline Pending & 22 & 19.5 & 13 & 8.9 & 5 & 5.9 & 8 & 8 & 12 & 20 & 24 & 47.1 \\
\hline Resolved complaints at the unit & 82 & 72.6 & 127 & 87 & 80 & 94.1 & 30 & 30 & 46 & 76.7 & 20 & 39.2 \\
\hline Responded complaints by other managements & 9 & 8 & 6 & 4.1 & 0 & 0.0 & 5 & 5 & 2 & 3.3 & 7 & 13.7 \\
\hline Unknown (not reviewed) & 0 & 0.0 & 0 & 0.0 & 0 & 0.0 & 57 & 57 & 0 & 0.0 & 0 & 0.0 \\
\hline Total & 113 & 100 & 146 & 100 & 85 & 100 & 100 & 100 & 60 & 100 & 51 & 100 \\
\hline Feedback given to the complainant & 91 & 100 & 133 & 100 & 80 & 100 & 35 & 100 & 39 & 81.3 & 30 & 100 \\
\hline Resolved complaints with no feedback to complainants & 0 & 0.0 & 0 & 0.0 & 0 & 0.0 & 0 & 0.0 & 9 & 18.8 & 0 & 0 \\
\hline Total & 91 & 100 & 133 & 100 & 80 & 100 & 35 & 100 & 48 & 100 & 30 & 100 \\
\hline
\end{tabular}

is no significant difference between the qualities of treatment provided by the female specialists who were complained about and those who were not. This is confirmed in another study that the quality of treatments is not an important factor of patients' complaints. In the present study, however, this factor is among the issues with high complaints (19).

Findings of the present study indicate that the highest number of complaints was registered in the third quarter of 2012 (348 cases) and the lowest number of complaints (200 cases) was in the first quarter of 2013. In the third quarter of the studied period, the largest number of complaints was about the hospital's units (229 cases) and in the first quarter of 2013 (the last third months of the studied period), the lowest number of complaints was about the hospital's units (94 cases). The most important case of complaint was about private booths in almost all months (Table 2). Patients and their attendants often use private booths. If these booths are supervised regularly, the number of the complaints will decrease to a great extent. Supervising the observation of ethics and respects as well as monitoring compliance with tariff prices are very important.

With respect to complaints about the units, findings show that the lowest number of complaints was about diagnosis and support units. Since patients and their attendants have little direct contact with support units, the rate of complaints are low about these units. The accountability of the hospital's various deputies to complaints can play a decisive role in responding to complaints and giving feedback to patients and their attendants; this issue needs special planning too.

\section{Limitation}

The present research suffers several limitations including: incomplete recording of data related to complaints, the lack of access to all the data recorded in the hospital divided into the months, the lack of a comprehensive system for filing complaints in the hospital. Future research can focus on the qualitative assessment of complaint causes divided into different treatment groups and on the examination of practical strategies to control complaints.

\section{Conclusion}

Because the rate of complaints in hospitals particularly about the treatment staff is high, these complaints may be considered as experiences for modifications and amendments of hospitals' future performances. Generally, the existence of complaints in a system may be an indication of gaps in case of providing healthcare.

\section{Acknowledgements}

Thanks go to those who contributed in this research. Special thanks also go to managers of the hospital and the unit for reviewing complaints.

\section{Ethical issues}

The Ethics Committee of Isfahan University of Medical Sciences approved the study (Project No: 291298).

\section{Competing interests}

The authors declare that they have no competing interests.

\section{Authors' contributions}

AJ initiated the idea. AJ, EK, and MJJ facilitated the process of data gathering. MM and RM contributed to the literature review, the development of the protocol, and managing the data gathering. AJ contributed to study administration, data analysis, interpretation of results and writing the first draft of the manuscript with MJJ, EK, MM, and RM. All authors reviewed the final manuscript. $\mathrm{AJ}$ is the study guarantor.

\section{Authors' affiliations}

'Health Management and Economics Research Center, School of Management and Medical Information, Isfahan University of Medical Sciences, Isfahan, Iran. ${ }^{2}$ School of Management and Medical Information, Student Research Committee, Isfahan University of Medical Sciences, Isfahan, Iran. ${ }^{3}$ Research Center for Modeling in Health, Institute for Futures Studies in Health, Kerman University of Medical Sciences, Kerman, Iran. ${ }^{4}$ Medical Informatics Research Center, Institute for Futures Studies in Health, Kerman University of Medical Sciences, Kerman, Iran. ${ }^{5}$ Research Center for Health Services Management, Institute for Futures Studies in Health, Kerman University of Medical Sciences, Kerman, Iran.

\section{References}

1. Fong N. Western Australian Clinical Governance Guidelines. Information series no.1, 2. [internet]. 2005. Available from: http:// www.safetyandquality.health.wa.gov.au/docs/clinical_gov/1.2\%20 Clinical\%20Governance\%20Guidelines.pdf

2. Starey N. What is clinical governance? Hayward Medical Communications 2001; 1: 1-9.

3. Kalroozi F, Dadgari F, Zareiyan A. Patients' satisfaction from health care group in patient's bill of right observance. Journal of Military Medicine 2010; 12: 143-8.

4. Jolaee S. [Phenomenological explanation of patient rights]. Tehran: Tehran University of Medical Sciences; 2007.

5. Rashidian A. [Rule of clinical services at the Tehran University of Medical Sciences]. Tehran: The capital of academic policy development in health systems; 2009.

6. Akhlaghi M, Tofighizavare H, Samadi F. Malpractice complaints referred to Medical Commission Legal Medicine Organization in the field of obstetrics and gynecology during the years 2001 and 2002; causes and methods of prevention. Scientific Journal of Forensic Medicine 2004; 10: 70-4.

7. Joolaee S, Nikbakht-Nasrabadi A, Parsa-Yekta Z, Tschudin V, Mansouri I. An Iranian perspective on patients' rights. Nurse Ethics 2006; 13: 488-502. 
8. Hedaiati M, Nejadnik M, Setare M. The Factors Affecting the Final Verdict in Medical Errors Complaints. Journal of Isfahan Medical School 2012; 29: 1497-1509.

9. Hejazi S, Zeinali M, Farokheslamlou H. [Study of Pediatric Malpractice Claims Registered at URMIA Medical Council during 10 Year Period (1995-2005)]. Urmia Medical Journal 2009; 20: 123-30.

10. Rafizadeh Tabai Zavareh S, Haj Manoochehri H, Nasaji Zavareh $M$. Examination of general practitioners' negligence frequency in complaints filed with Tehran's Commission of Forensic Medicine from 2003 to 2004. Scientific Journal of Forensic Medicine 2007; 13: $152-7$.

11. Mirzaaghai F, Moeinfar Z, Eftekhari S, Rashidian A, Sedeghat $M$. [Reviewing complaints recorded at three hospitals affiliated to Tehran University of Medical Sciences and the factors affecting it from April 2007 to February 2008]. Hospital 2011; 10: 19-28.

12. Sedaghat S. [Review Products]. Razi Journal 2011; 22: 87-90.

13. Parsapour A, Bagheri A, Larijani B. [Patient rights in Iran]. Irainian Journal of Medical Ethics and History of Medicine 2009; 3: 39-47.

14. Haghi $\mathrm{S}$, Zare $\mathrm{G}$, Ataran $\mathrm{H}$. Factors affecting the surgical team convicted of malpractice claims and Quality of Investigating the claims of the Medical Council of Mashhad. Scientific Journal of Forensic Medicine 2005; 11: 141-5.

15. Rangrazjeddi F, Rabiee, R. [Patient's Bill of Rights in Kashan's Governmental Hospitals (2003)]. Journal of Kermanshah University of Medical Sciences 2005; 9: 62-71.

16. Davati A, Seyad Mortaz SA, Azimi A, Arbab Soleimani S. [A study on the knowledge of general practitioners about the charter of patients' rights]. Medical Daneshvar 2011; 18: 81-8.

17. Athar M, Ostad Ali Makhmalbaf M, Davati A. [Study of medical malpractice complaints in the field of dermatology and cosmetic, in the coroner's Office of Forensic Medicine,province of Tehran, during 2002 to 2010]. Dermatology and Cosmetic 2011; 2: 17-29.

18. Jafarian A, Parsapour A, Hajtarkhani AH, Asghari F, Emami Razavi SA, Yalda A. [Survey on Complaints Records in the Medical Council of Tehran in 1991,1996,2001]. Irainian Journal of Medical Ethics and History of Medicine 2009; 2: 67-73.

19. Entman SS, Glass CA, Hickson GB, Githens PB, WhettenGoldstein K, Sloan FA. The relationship between malpractice claims history and subsequent obstetric care. JAMA 1994; 272: 1588-91.

\section{Key Messages}

Implications for policy makers

- Setting policies to reduce complaints about medical and nursing staff

- Enforcing requirement for all hospital's units to participate in reviewing the complaints

- Developing a comprehensive system for complaints review in hospitals

\section{Implications for public}

A criterion which can be used to improve health services is to investigate complaints and their causes. Complaintrelated data are employed as a means of learning from dissatisfied patients. Patients' complaints are representations of dissatisfaction with healthcare services provided by hospital staff and indications of gaps in service provision system which effects hospitals' deficiencies. If a systematic approach to handle patients' complaints is developed in hospitals, not only their performance improves, but their quality of treatment will enhance too. Comparing and sharing complaint-related data among hospitals are critical and may identify the most troublesome areas and at the same time can be employed for strategic planning. Lessons learnt from the complaints in one hospital may also be used to tackle similar deficiencies in other hospitals. 